\title{
Frequency and associations of chronic kidney disease among gout patients from a University Teaching Hospital in Nigeria
}

\author{
Akpabio Akanimo Akpabio ${ }^{1}$, Pam Stephen Dung-gwom², Babatunde Hakeem Olaosebikan², \\ Olufemi Oladipo Adelowo ${ }^{3}$
}

${ }^{1}$ Internal Medicine Department, University of Uyo Teaching Hospital, Uyo, Akwa Ibom State, Nigeria

${ }^{2}$ Department of Medicine, Jos University Teaching Hospital, Jos, Plateau State, Nigeria

${ }^{3}$ Department of Medicine, Lagos State University Teaching Hospital, Ikeja, Lagos, Nigeria

\begin{abstract}
Objectives: To highlight common precipitants and co-morbidities of gout in Nigerians; determine the frequency of chronic kidney disease (CKD) in Nigerian gout patients, as well as identify significant associations of CKD in gout patients.

Material and methods: Retrospective cross-sectional study of gout cases seen at the Rheumatology Clinic of the Lagos State University Teaching Hospital over five years from January 2011 to December 2015. Gout was diagnosed using the 1977 American Rheumatism Association (ARA) criteria. Clinical and laboratory data were extracted and examined for the presence of CKD defined using Kidney Disease Improving Global Outcomes (KDIGO) 2012 guidelines as estimated glomerular filtration rate (eGFR, CKD-EPI) $<60 \mathrm{mls} / \mathrm{min} / 1.73 \mathrm{~m}^{2}$ body surface area for $>3$ months.

Results: One hundred and six gout patients were identified representing $4.5 \%$ out of a total of 2330 cases seen during the study period. There were 94 males and 12 females. Oligoarthritis was most frequent (41.5\%) with the knee mostly affected (20.1\%). Diuretic use was the most frequent precipitant (37.9\%) with hypertension the commonest co-morbidity (62.9\%). Of 70 patients with complete results, 29 had eGFR (CKD-EPI) $<60 \mathrm{mls} / \mathrm{min}(41.4 \%)$. Age, proteinuria, body mass index (BMI) and packed cell volume (PCV) were significant associations of CKD. Gout patients with CKD were significantly older (61.79 vs. 54.41 years, $p=0.003$ ) with a significantly higher proportion developing proteinuria (15 vs. 4 patients, $p \leq 0.0001$ ) compared to those without CKD. In contrast, those with CKD had a significantly lower BMI (27.31 vs. $\left.29.65 \mathrm{~kg} / \mathrm{m}^{2}, p=0.026\right)$ and PCV (31.97 vs. $37.95 \%, p=$ 0.005).

Conclusions: Thiazide diuretic use is the most common precipitant while hypertension is the commonest comorbidity in Nigerian gout patients. About two in five Nigerian gout patients had chronic kidney disease at presentation with age, proteinuria, BMI and PCV as significant associations. It is thus imperative to screen for chronic kidney disease when managing gout patients.
\end{abstract}

Key words: gout, chronic kidney disease, Nigerians, associations.

\section{Introduction}

Gout is a crystal deposition disease which arises when supersaturation of body tissues with urate occurs, leading to the formation of monosodium urate (MSU) crystals in and around joints. It is the most prevalent inflammatory arthritis in men and is associated with an impaired quality of life [1]. Uric acid is the end product of purine metabolism in humans. Hyperuricemia (serum urate $>6.8 \mathrm{mg} / \mathrm{dl}$ ) results from either urate over-produc- 
tion, under-excretion or both. Combined with favorable local factors, urate crystals deposit within tissues and subsequently initiate an inflammatory reaction [2].

According to the Global Burden of Diseases Study 2016, global prevalence of gout is estimated at about 33.97 million with an incidence of 6.43 million. Gout contributed 1.07 million to the number of Years Lived with Disability (YLDs) in the same year [3]. The US National Health and Nutrition Examination Survey (NHANES) has shown an increasing prevalence of gout from 2.9\% (1988-1994) to 3.9\% (2007-2008) with African Americans being mostly affected [4]. Similar reports from Europe and elsewhere have also shown a rising trend $[5,6]$. While previously thought to be rare, recent reports from Africa indicate an upsurge in prevalence in line with changing lifestyle and diet as well as increasing use of diuretics and low dose aspirin [7-9]. Gout has been associated with various co-morbidities including: hypertension, diabetes, obesity, dyslipidemia, coronary heart disease, stroke, osteoarthritis and chronic kidney disease $[10,11]$.

Chronic kidney disease (CKD) has been defined by the Kidney Disease Improving Global Outcomes (KDIGO) 2012 guidelines as: abnormalities of kidney structure or function, present for three or more months, with implications for health and is classified based on cause, glomerular filtration rate (GFR) category, and albuminuria category [12]. A bidirectional relationship exists between gout and CKD. Although CKD is an independent risk factor for gout, the latter may predispose to renal disease via several mechanisms such as: hyperuricemia, chronic inflammation, co-morbid hypertension and diabetes, and frequent use of non-steroidal anti-inflammatory drugs (NSAIDs) [13]. The burden of CKD in sub-Saharan Africa is significant, estimated at $13.9 \%$ overall in a recent metaanalysis [14]. Recent Nigerian reports show a rising prevalence ranging from $10.4-24.2 \%$ [15, 16] [using estimated GFR (eGFR) < $60 \mathrm{mls} / \mathrm{min}$ ]. Higher figures of $12.4-29.7 \%[15,17]$ have been also been reported (using persistent proteinuria). There have been relatively few reports examining the frequency of chronic kidney disease among black Africans with gout. In contrast, population based studies from the US and UK have shown prevalences of $19.9 \%$ and $24 \%$ respectively among Caucasian gout patients [13, 18].

Two previous studies of Nigerian gout patients have shown disparate frequencies of $0.7 \%$ and $18.8 \%$ among gout patients with co-morbidities using clinical history only $[7,10]$. Objective measures such as: eGFR or proteinuria were not utilized. To the best of our knowledge, there has been no documented study reporting the frequency of CKD in Nigerian gout patients. This paper aims to highlight common precipitants and co-morbidities of gout in Nigerians, determine the frequency of chronic kidney disease (CKD) among Nigerian gout patients, as well as identify significant associations of CKD in gout patients.

\section{Material and methods}

This is a retrospective cross-sectional study of CKD among gouty arthritis patients seen at the Lagos State University Teaching Hospital in Lagos State over a five year period from January 2011 to December 2015. Results of radiographic investigations were also obtained where available. Patients received standard therapy with Colchicine, Allopurinol, Febuxostat and NSAIDs (non-steroidal anti-inflammatory drugs). Allopurinol dosage was reduced while NSAIDs were avoided where renal dysfunction was established. Febuxostat was prescribed in such cases. Underlying co-morbidities were also treated with appropriate medications. Gout patients with chronic kidney disease (stages 3-5) were jointly managed with nephrologists.

Only patients aged 18 years and above who met the criteria for gout valid during the observation period (1977 American Rheumatism Association - ARA criteria) were included in the study [19]. The criteria has a sensitivity and specificity of $70 \%$ and $78.8 \%$ respectively when compared with the gold standard of polarizing microscopy which is not readily available in Nigeria and is only of practical use where needle aspiration was possible as in large joints. In spite of this, seven patients had polarized microscopy.

Body mass index (BMI) was calculated using the formula: weight $(\mathrm{kg}) /$ height $^{2}\left(\mathrm{~m}^{2}\right)$. BMI was categorized as 18.5-24.9 normal, 25-29.9 overweight, $\geq 30$ obese [20]. Chronic kidney disease was defined based on the KDIGO 2012 guidelines using the GFR parameter of $<60 \mathrm{ml}$ $\mathrm{min} / 1.73 \mathrm{~m}^{2}$ body surface area for more than three months [12].

Glomerular filtration rate (GFR) was estimated using the Chronic Kidney Disease Epidemiology Collaboration equation (CKD-EPI) [21] as follows:

$\left[141 \times \min (\mathrm{Cr} / \mathrm{k}, 1)^{\alpha} \times \max (\mathrm{Cr} / \mathrm{k}, 1)^{-1.209} \times 0.993^{\text {age }} \times 1.018\right.$ if female $\times 1.159$ if black];

where $\mathrm{Cr}=$ creatinine $(\mathrm{mg} / \mathrm{dl}), \mathrm{k}=0.7$ for females, 0.9 for males; $\alpha=-0.329$ for females, -0.411 for males.

It has been validated in a Nigerian population and is known to give a better GFR estimation especially in subjects with eGFR > $60 \mathrm{ml} / \mathrm{min}$ compared with the Modification of Diet in Renal Disease (MDRD) equation [22]. 
Dipstick proteinuria was graded as $1+(30 \mathrm{mg} / \mathrm{dl})$, $2+(100 \mathrm{mg} / \mathrm{dl})$, and 3+ (500 mg/dl) or negative [16] Hypertension was defined as BP was $\geq 140 / 90 \mathrm{~mm} \mathrm{Hg}$ or current use of antihypertensive medications [16]. Diabetes mellitus was diagnosed based on the WHO criteria of fasting plasma glucose of $\geq 7 \mathrm{mmol} / \mathrm{l}$ and/or random plasma glucose of $\geq 11.1 \mathrm{mmol} / \mathrm{l}$ and above or current treatment for diabetes [23]. Dyslipidemia was defined according to the National Cholesterol Education Program/Adult Treatment Panel III (NCEP/ATP III) guidelines [24] as: total cholesterol > $5.17 \mathrm{mmol} / /(>200 \mathrm{mg} / \mathrm{dl})$; low density lipoprotein $>3.36 \mathrm{mmol} / \mathrm{l}$ (> $130 \mathrm{mg} / \mathrm{dl}$ ); high density lipoprotein: $<1.03 \mathrm{mmol} / \mathrm{l}(<40 \mathrm{mg} / \mathrm{dl})$ for males and $<1.3 \mathrm{mmol} / \mathrm{l}(<50 \mathrm{mg} / \mathrm{dl})$ for females; triglycerides $>1.7 \mathrm{mmol} / \mathrm{l}$ (> $150 \mathrm{mg} / \mathrm{dl})$.

Data analysis was performed using Statistical Package for Social Sciences (SPSS) version 20. Frequencies were reported as percentages. Independent $t$ test was used to compare quantitative variables between the two groups while chi square test was used for qualitative variables. Statistical significance was set at $p<0.05$.

Ethical Committee approval was obtained for the study.

\section{Results}

A total of 106 gout patients were identified, representing $4.5 \%$ out of a total of 2330 cases seen in the rheumatology clinic over the study period. There were 94 males (88.7\%) and 12 females (11.3\%) giving male to female ratio $7.8: 1$

The mean age of the patients was $56.4 \pm 10.1$ years. The mean age by gender was $56.5 \pm 10.2$ years for males and $55.7 \pm 9.8$ years for females with no significant dif-

Table I. Age and sex distribution of 106 gout patients

\begin{tabular}{|lccc|}
\hline Parameter & Male & Female & Total \\
\hline Frequency $(\%)$ & $94(88.7)$ & $12(11.3)$ & 106 \\
\hline $\begin{array}{l}\text { Age (years) } \\
{[\text { mean } \pm \text { SD] }}\end{array}$ & $56.5 \pm 10.2$ & $55.7 \pm 9.8$ & $56.4 \pm 10.1$ \\
\hline
\end{tabular}

Table II. Proportion of precipitants and comorbidities in gout subjects

\begin{tabular}{|lc|lc|}
\hline Precipitants & $\%$ & Comorbidities & $\%$ \\
\hline Thiazide diuretics & 37.9 & Hypertension & 62.9 \\
\hline Low-dose aspirin & 22.5 & Dyslipidemia & 41.5 \\
\hline Alcohol & 19.8 & Diabetes Mellitus & 19 \\
\hline Diet & 19.8 & Obesity & 16 \\
\hline
\end{tabular}

ference $(p=0.795)$. Table I shows the age and sex distribution of the study subjects.

Use of thiazide diuretics was the most common precipitant used drugs (37.9\%) while alcohol use and high-purine diet were the least common (19.8\%). Seventy six patients $(71.7 \%)$ had comorbidities of which hypertension was the most common (62.9\%). The average $\mathrm{BMI}$ of the study population was $29.8 \pm 2.1 \mathrm{~kg} / \mathrm{m}^{2}$ and $16 \%$ of the subjects were obese while $41.5 \%$ had dyslipidemia of which hypercholesterolemia predominated. Table II shows the proportions of precipitants and comorbidities.

Examination of the musculoskeletal system revealed that arthritis was confirmed in 273 joints in 106 gout patients. Most often it was oligoarthritis $-41.5 \%$ of cases, followed by polyarthritis $-35.8 \%$ and monarthritis $22.7 \%$. The knee joint was the most frequently affected (20.1\%) and the first metatarsophalangeal (MTP I) joint was affected in $19.8 \%$ of the patients. The least affected joints were the elbow and wrist respectively (8.8\% each). Tophi were present in 36 patients (32\%). Figure 1 presents the type and frequency of joint involvement in the group of examined patients.

There were significant differences by gender in disease duration and annual number of gout attacks. Males had gout for a median of 12 months (range 0.03-240); females 0.17 months (range 0.03-2.0) $(p<0.001)$. Males also had more frequent attacks per year 3.0 (range 1-10) compared to females 1.0 (range 1-4) ( $p=0.016)$.

Joint erosions (50\%) were the commonest feature in the twenty-two patients with available radiographs. Other features seen were osteophytes (26\%), soft tissue swelling (13\%) and joint space narrowing (11\%). Urinalysis results available in $66 \%(n=77)$ gout patients and among them 19

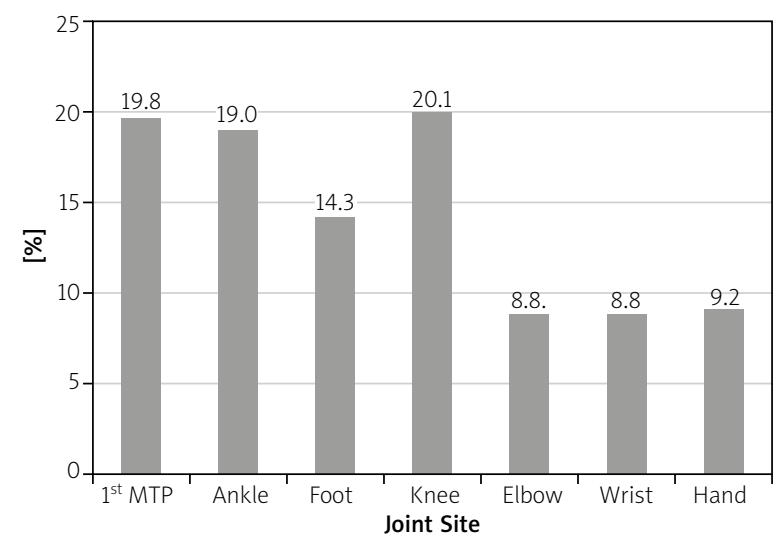

Fig. 1. Pattern of joint involvement in 106 gout patients. 
Table III. Comparison of clinical and laboratory parameters among 70 gout patients

\begin{tabular}{|lccc|}
\hline Variable & CKD $(n=29)$ & No CKD $(n=41)$ & $p$-value \\
\hline Age $($ years $)$ & $61.79 \pm 11.19$ & $54.41 \pm 8.65$ & 0.003 \\
\hline BMI $\left(\mathrm{kg} / \mathrm{m}^{2}\right)$ & $27.31 \pm 5.00$ & $29.65 \pm 2.73$ & 0.026 \\
\hline SBP $(\mathrm{mm} \mathrm{Hg})$ & $149.07 \pm 24.89$ & $138.72 \pm 21.04$ & 0.070 \\
\hline DBP $(\mathrm{mm} \mathrm{Hg})$ & $85.57 \pm 11.96$ & $87.43 \pm 11.63$ & 0.523 \\
\hline PCV $(\%)$ & $31.97 \pm 6.94$ & $37.95 \pm 5.74$ & 0.005 \\
\hline WBC $\left(\times 10^{3} / \mathrm{l}\right)$ & $7.33 \pm 2.91$ & $7.82 \pm 3.64$ & 0.640 \\
\hline ESR $(\mathrm{mm} / \mathrm{hr})$ & $88.36 \pm 37.30$ & $66.85 \pm 39.28$ & 0.093 \\
\hline Urate $(\mathrm{mg} / \mathrm{dl})$ & $10.78 \pm 2.68$ & $9.81 \pm 2.69$ & 0.138 \\
\hline $\begin{array}{l}\text { Total cholesterol } \\
(\mathrm{mmol} / \mathrm{l})\end{array}$ & $5.37 \pm 1.31$ & $5.44 \pm 1.60$ & 0.860 \\
\hline
\end{tabular}

(27.1\%) had proteinuria [ $8.6 \%$ had mild (1+), $11.4 \%$ moderate $(2+)$ and $7.1 \%$ severe $(3+)$ proteinuria].

In 70 patients (66\%) serum creatinine results were recorded and eGFR (CKD-EPI) could be calculated for this subgroup. Finally 29 patients were demonstrated CKD based on an eGFR value $<60 \mathrm{mls} / \mathrm{min}$. Between them 19 were CKD in stage 3, 7 were in stage 4, while 3 patients were in stage 5 . Gout patients with CKD comprised of 28 males and 1 female. There was no significant difference by gender between gout patients with and without CKD ( $p=0.492$ ). Gout patients with CKD were significantly older (61.79 vs. 54.41 years, $p=0.003$ ) and also with a significantly higher proportion developing proteinuria (15 vs. 4 patients, $p \leq 0.0001$ ) compared to those without CKD. Although the CKD group had a higher mean uric acid (10.65 vs. $9.73 \mathrm{mg} / \mathrm{dl}$ ) compared to those without CKD, this was not statistically significant $(p=0.171)$. CKD patients had a significantly lower BMI (27.31 vs. 29.65 $\left.\mathrm{kg} / \mathrm{m}^{2}, p=0.026\right)$ and PCV (31.97 vs. $\left.37.95 \%, p=0.005\right)$.

There was no significant difference in the occurrence of tophi, hypertension, diabetes mellitus and dyslipidemia between both groups. Other clinical and laboratory parameters assessed were as shown in Table III.

Univariate analysis showed age, presence of proteinuria, body mass index and packed cell volume to be significant associations of CKD in gout patients.

\section{Discussion}

Gout is increasingly being reported worldwide [4-6] and this has been mostly attributed to changes in lifestyle and diet. Other reasons are the frequent use of diuretics and low dose aspirin. Recent reports from Africa have also highlighted a similar trend [7-10]. This study identified a total of 106 gout patients (4.5\%) out of all
2330 patients who attended the rheumatology clinic within the five years of this study. This represents an increase in prevalence from the 146 cases recorded over a ten year period in a previous Nigerian study [7]. The characteristic male preponderance reported in the West $[4,5]$ is evident in our study with a male: female ratio of $7.8: 1$. This differs from the $2.8: 1$ and $3.6: 1$ in previous Nigerian reports $[12,13]$ but is similar to the finding from South Africa (6.6:1) [9] and Kenya (9.5:1) [25]. The reason for the apparent difference is unclear but may be due to patient selection.

The mean age of 56.4 years is similar to 53.4 years and 54.3 years previously reported from Nigeria [7] and South Africa [26] respectively. It is also similar to the finding from Germany [5] (58.6 years) and is in keeping with the expected onset of gout in middle age in both males and females.

Among our patients, median duration of gout before presentation was 12 months with a very wide range (0.03-240 months) compared to a mean of 3.6 years from a previous Nigerian study [7] and 6 years from Togo [27]. This variation may reflect improved awareness with earlier referral and presentation.

Gout precipitants were presented in 68 patients (64\%) were treated with thiazide diuretics (37.9\%) and the lowest (alcohol and diet $19.8 \%$ each). Hypertension is the most frequent comorbidity with gout and since thiazide diuretics are commonly used drugs to treat hypertension in blacks leads to frequent flares. The proportion with diuretic use was comparable to that reported by Cassim et al. [9] in South Africa (44.8\%) but less than that reported by Kodio et al. [8] in Mali (64\%). This is most likely due to the fact that the latter study contained a high proportion of patients with chronic renal failure (37\%) who could have been taking additional loop diuretics. The frequency of alcohol use in our study $(19.8 \%)$ is similar to that of a previous Nigerian study by Adelowo et al. [7] (17.8\%) but comparatively lower than that from Togo [27] (83.\%) and Kenya [25] (100\%) and may reflect socio-cultural and religious differences.

While most other African studies showed that monoarticular involvement was most frequent (Table IV) this study showed that oligoarticular presentation was the most common (41.5\%). This may be attributed to the fact that our study patients had a higher mean ESR (70.6 $\pm 37.5 \mathrm{~mm} / \mathrm{hr}$ ) compared to the study by Adelowo et al. [7] with mean ESR ( $45.4 \pm 37.6 \mathrm{~mm} / \mathrm{hr})$ and this could have accounted for the more severe presentation. The knee joint was most common affected (20.1\%). This is similar to the findings by Adelowo et al. [7] (55.5\%) and Cassim et al. [9] (85\%) and may be explained by possi- 
Table IV. Comparison of clinical findings from different African studies on gout

\begin{tabular}{|c|c|c|c|c|c|c|c|}
\hline & $\begin{array}{l}\text { Adelowo et al. } \\
\text { [7] (Nigeria 1) }\end{array}$ & $\begin{array}{l}\text { Oguntona [10] } \\
\text { (Nigeria 2) }\end{array}$ & $\begin{array}{l}\text { Cassim et al. [9] } \\
\text { (S. Africa) }\end{array}$ & $\begin{array}{c}\text { Oyoo [25] } \\
\text { (Kenya) }\end{array}$ & $\begin{array}{c}\text { Mijiyawa [27] } \\
\text { (Togo) }\end{array}$ & $\begin{array}{l}\text { Kodio [8] } \\
\text { (Mali) }\end{array}$ & $\begin{array}{l}\text { Present study } \\
\text { (Nigeria 3) }\end{array}$ \\
\hline$M$ : F ratio & $2.8: 1$ & $3.6: 1$ & $6.6: 1$ & $9.5: 1$ & & $1: 1.2$ & $7.8: 1$ \\
\hline \multicolumn{8}{|l|}{ Pattern \% } \\
\hline MonoA. & 50 & & 37.4 & 47.6 & 59 & 36 & 22.6 \\
\hline OligoA. & 35.6 & & 28 & 19.1 & & & 41.5 \\
\hline PolyA. & 14.4 & & 34.6 & 33.3 & 41 & & 35.8 \\
\hline \multicolumn{8}{|l|}{ Site \% } \\
\hline Knee & 55.5 & & 85 & 14.1 & & 92 & 20.1 \\
\hline MTP & 14.4 & & 74.8 & 34.9 & & & 19.8 \\
\hline Ankle/feet & 34.2 & & 61.7 & 18.9 & & & 19.0 \\
\hline \multicolumn{8}{|l|}{ Assoc. \% } \\
\hline $\mathrm{Htn}$ & 49.3 & 62.5 & & 61.5 & 25 & 76 & 62.9 \\
\hline Dyslipid. & & & & & & & 41.5 \\
\hline CKD & 0.7 & 18.8 & & & & 37 & 41.4 \\
\hline $\mathrm{DM}$ & 4.9 & 25 & & 7.7 & & 13 & 19.0 \\
\hline Obesity & 12.7 & 37.5 & & 90.5 & 40 & 83 & 16.0 \\
\hline Tophi \% & 6.2 & & 58 & 19 & 21 & 4 & 32 \\
\hline
\end{tabular}

ble coexisting knee osteoarthritis. This however is different from the finding from Kenya which reported first metatarsophalangeal involvement as the most frequent (34.9\%) [25]. As was mentioned above hypertension was the most common comorbidity in our gout patients $62.9 \%$. This observation is in agreement with other studies [7, 10, 25]. Among all studied patients $16 \%$ were obese, based on $\mathrm{BMI}>30 \mathrm{~kg} / \mathrm{m}^{2}$, though only $6.9 \%$ had obesity from medical history. This is similar to a previous Nigerian study [7] but less than were reported by others [ $8,10,25,27]$. There differences may have arisen because some studies reported overweight and obese patients together $[8,27]$. Among our study subjects $41.5 \%$ had dyslipidemia which portends an increased cardiovascular risk. Adelowo et al. [7] reported a mean total cholesterol of $211 \mathrm{mg} / \mathrm{dl}$ among their patients which is comparable to the mean of $205 \mathrm{mg} / \mathrm{dl}$ noted in presented study. The established association between gout and the metabolic syndrome has also been highlighted by others [5, 26].

The frequency of CKD among gout patients from our study was $41.4 \%$. This is much more than the $18.8 \%$ reported by Oguntona [10] which was limited in that only patient-reported history of CKD was used. Objective measures such as estimated GFR or proteinuria were not utilized. It must also be noted that the previous studies by Adelowo et al. [7] and Oguntona [10] were from a private rheumatology clinic whereas this present study is from a University Teaching Hospital and this may affect patient characteristics.

Our frequency is comparable to that of Kodio et al. from Mali [8] (37\%) and Fuldeore et al. from United States (39\%) [28]. The former used creatinine clearance $<60 \mathrm{ml} / \mathrm{min}$ (which is less accurate than eGFR) while the latter defined CKD as eGFR $<90 \mathrm{ml} / \mathrm{min}$. A higher frequency of $54.5 \%$ has been reported from Taiwan [29] using the MDRD formula. Our finding is however, much more than the pooled prevalence of $19.9 \%$ from the US [11] and 24\% from a recent European meta-analysis [13]. This may be due to methodological differences. Renal dysfunction in gout patients is thought to occur via different mechanisms such as: hyperuricemia, chronic inflammation, co-morbid hypertension and diabetes, and also use of NSAIDs [13].

Age, proteinuria, BMI and packed cell volume (PCV) were significant associations of CKD in gout patients. Gout patients with CKD in our study were significantly older (Table I) in agreement with other studies [28, 30]. Other parameters compared revealed significantly lower BMI and PCV as shown in Table III. This can be explained by the reduced erythropoietin production with onset of renal dysfunction. Gout patients with CKD also tend to have greater dietary restrictions in addition to diuretic therapy which could result in lower BMI. This study showed no statistically significant difference in Urate levels of both groups as noted by others [30]. 
Cheyoe et al. [29] however, identified other factors such as hypertension, dyslipidemia and serum uric acid concentration to be significantly associated with CKD in gout. The reason for this difference is unclear. The presented study has been able to identify a $41.4 \%$ frequency of CKD among Nigerian gout patients. Older age, presence of proteinuria, lower BMI and PCV have also been shown to be significant associations of CKD in gout. This highlights the importance of prompt referral, adequate patient education, proper management and regular follow-up of gout patients in order to reduce the frequency of chronic kidney disease with its attendant financial and adverse protection. Our study had some limitations: the cross-sectional study design cannot explain causation and occasionally yields missing data. The hospital-based setting may not always represent the true estimate in the whole community.

\section{Conclusions}

From this study, gout in Nigerians commonly occurs in the $5^{\text {th }}$ decade just as in Caucasian populations. Although the knee joint was most frequently affected in our patients, it is possible that some cases of pseudogout or knee osteoarthritis flare may have been misdiagnosed as gout.

Similar to what has been previously reported elsewhere, gout is often associated with comorbidities one of which is chronic kidney disease. About two in five Nigerian gout patients have CKD with similar figures noted by others. It is thus imperative for doctors to always screen for CKD after diagnosing gout.

Dr. Udeme Ekrikpo for his insightful comments and assistance with part of the analysis.

The authors declare no conflict of interest.

\section{References}

1. Roddy E, Choi H. Epidemiology of Gout. Rheum Dis Clin North Am 2014; 40: 155-175.

2. Choi HK, Mount DB, Reginato AM. Pathogenesis of gout. Ann Intern Med 2005; 143: 499-516.

3. Vos T, Abajobir AA, Abate KH, et al. Global, regional, and national incidence, prevalence, and years lived with disability for 328 diseases and injuries for 195 countries, 1990 \& 2013; 2016: a systematic analysis for the Global Burden of Disease Study 2016. Lancet 2017; 390: 1211-1259.

4. Zhu Y, Pandya BJ, Choi HK. Prevalence of gout and hyperuricemia in the US general population: The National Health and Nutrition Examination Survey 2007-2008. Arthritis Rheum 2011; 63: 3136-3141.
5. Annemans L, Spaepen E, Gaskin M, et al. Gout in the UK and Germany: prevalence, comorbidities and management in general practice 2000-2005. Ann Rheum Dis 2008; 67: 960-966.

6. Winnard D, Wright C, Jackson G, et al. Gout, diabetes and cardiovascular disease in the Aotearoa New Zealand adult population: co-prevalence and implications for clinical practice. N Z Med J 2012; 126: 53-64.

7. Adelowo O, Umar A, Oguntona S. Gouty arthritis in Nigerians: clinical and laboratory correlates. African Journal of Rheumatology 2014; 2: 23-28.

8. Kodio B, Pamanta IS, Sylla C,et al. Step wise approach of gout in the Rheumatology ward of Point-G University Teaching Hospital of Bamako, Mali. African Journal of Rheumatology 2015; 3: 22-26.

9. Cassim B, Mody GM, Deenadayalu VK, Hammond MG. Gout in black South Africans: a clinical and genetic study. Ann Rheum Dis 1994; 53: 759-762.

10. Oguntona SA. Gout and Its Comorbidity among Nigerians. J Med Biol Sci 2013; 3: 26-32.

11. Sattui SE, Singh JA, Gaffo AL. Comorbidities in patients with crystal diseases and hyperuricemia. Rheum Dis Clin North Am 2014; 40: 251-278.

12. Global KDI, Group OKCW. KDIGO 2012 Clinical Practice Guideline for the Evaluation and Management of Chronic Kidney Disease. Kidney Inter 2013; Suppl 2013;3: 1-150.

13. Roughley MJ, Belcher J, Mallen CD, Roddy E. Gout and risk of chronic kidney disease and nephrolithiasis: meta-analysis of observational studies. Arthritis Res Ther 2015; 17: 90.

14. Stanifer JW, Jing B, Tolan S, et al. The epidemiology of chronic kidney disease in sub-Saharan Africa: a systematic review and meta-analysis. The Lancet Global Health 2014; 2: e174-e181.

15. Afolabi MO, Abioye-Kuteyi EA, Arogundade FA, Bello IS. Prevalence of chronic kidney disease in a Nigerian family practice population. South African Family Practice 2009; 51: 132-137.

16. Akpan EE, Ekrikpo UE, Udo Al. Risk factors for chronic kidney disease in Urban Uyo, South-South, Nigeria. Saudi J Kidney Dis Transpl 2016; 27: 1011-1017.

17. Fatiu A, Abubakr S, Muzamil H, et al. Undiagnosed hypertension and proteinuria in a market population in lle-lfe, Nigeria. Arab J Nephrol Transplant 2011; 4: 141-146.

18. Zhu Y, Pandya BJ, Choi HK. Comorbidities of gout and hyperuricemia in the US general population: NHANES 2007-2008. Am J Med 2012; 125: 679-687.

19. Wallace SL, Robinson H, Masi AT, et al. Preliminary criteria for the classification of the acute arthritis of primary gout. Arthritis Rheum 1977; 20: 895-900.

20. WHO Expert Consultation. Appropriate body-mass index for Asian populations and its implications for policy and intervention strategies. Lancet 2004; 363: 157-163.

21. Levey AS, Stevens LA. Estimating GFR using the CKD epidemiology collaboration (CKD-EPI) creatinine equation: more accurate GFR estimates, lower CKD prevalence estimates, and better risk predictions. Am J Kidney Dis 2010; 55: 622.

22. Uche C, Osegbe I. Comparison of CKD-EPI versus MDRD and Cockcroft-Gault equations to estimate glomerular filtration 
rate among stable homozygous sickle cell patients in Southwest Nigeria. Nigerian Journal of Clinical Practice 2017; 20: 816-821.

23. Organization WHO. Definition, Diagnosis, and Classification of Diabetes Mellitus and its Complications: Report of a WHO Consultation 1999; [publ. no. WHO/NCD/NCS/99.2].

24. Third Report of the National Cholesterol Education Program (NCEP) Expert Panel on Detection, Evaluation, and Treatment of High Blood Cholesterol in Adults (Adult Treatment Panel III) Final Report. Circulation 2002; 106: 3143-3145.

25. Oyoo G. Gout in patients attending a rheumatology clinic in Nairobi, Kenya. Health Line 2004; 8: 37-38.

26. Tikly M, Bellingan A, Lincoln D, Russell A. Risk factors for gout: a hospital-based study in urban black South Africans. Rev Rhum Engl Ed 1998; 65: 225-231.

27. Mijiyawa M, Oniankitan O. Risk factors for gout in Togolese patients. Joint Bone Spine 2000; 67: 441-445.

28. Fuldeore MJ, Riedel AA, Zarotsky V, et al. Chronic kidney disease in gout in a managed care setting. BMC Nephrol 2011; 12: 36.

29. Cheyoe N Kuning M, Lim A. The prevalence of Chronic Kidney Disease among gout patients in Nongjik Hospital, Pattani province. Thai Journal of Pharmaceutical Sciences 2012; 36: 144-149.

30. Shah A, Sundy JS. Predictors of Outcomes in Gout with Comorbid Chronic Kidney Disease. Arthritis Rheum 2011; 63 (Suppl 10): 1034. 